\title{
Feasibility and Optimization of Standalone PV-Biogas Hybrid Distributed Renewable System for Rural Electrification: A Case Study of a Cholistan Community
}

\author{
MUHAMMAD AHMED NAWAZ*, ABDUR RAHEEM*, RABIA SHAKOOR*, AND ZAIRA ANWAR**
}

RECEIVED ON 28.03.2018 ACCEPTED ON 25.08.2018

\section{ABSTRACT}

\begin{abstract}
Now-a-days, electricity has become the most significant part of human life. For this purpose, renewable energy sources as the emergent sources are introduced in the system. In Pakistan, in spite of having abundant renewable sources and favorable climate conditions, there are some remote areas where the extension of national grid is still absent. In this research paper, one of the remote area of Pakistan, Chak 6-DRB, a village of Cholistan, is considered for the hybrid renewable sources. This research has been implemented on HOMER (Hybrid Optimization Model for Electric and Renewable) software, in which two renewable sources; solar and anaerobic biogas have been implemented in terms of $\mathrm{COE}$ (Cost of Energy), NPC (Net Present Cost), costs of different equipment used and then find an optimal size and costs of the system. This HDRP (Hybrid Distributed Renewable Power) system contains anaerobic biogas, and solar system which yield most accurate and inexpensive results and are quite feasible for this remote area. This standalone generation and distribution model is also analyzed through HOMER including sensitivity parameters. In future, this role model of proposed hybrid renewable system would be very effective and helpful for other remote areas of the country for implementation.
\end{abstract}

Key Words: Hybrid Optimization Model for Electric and Renewable, Hybrid Systems, Renewable Systems, Standalone, Cost of Energy, Net Present Cost, Operation and Management Cost, Hybrid Distributed Renewable Power.

\section{INTRODUCTION}

1 ccording to International Energy Association, World Energy Outlook [1] there are 51 million people live without electricity in Pakistan and only $63 \%$ rural population has access to electricity. The situation of energy sector in Pakistan is quite bleak due to widening gap between demand and supply. The major reason of this state of energy sector is that, we had totally relied on non-renewable energy resources in past two decades in spite of world was and still moving towards renewable sources of energy. The panacea of this situation is only hidden in pursuing the renewable resources at national level.

Authors E-Mail: (ahmedbwp99@gmail.com, abdur.raheem@iub.edu.pk, rabia.shakoor@iub.edu.pk, eshmal.fatima@yahoo.com)

* Department of Electrical Engineering, The Islamia University of Bahawalpur, Bahawalpur, Pakistan.

** Department of Electrical Engineering, University of Engineering \& Technology, Taxila, Pakistan.

This is an open access article published by Mehran University Research Journal of Engineering and Technology, Jamshoro under the CC by 4.0 International License. 
A research of feasibility of HDRP for two villages of India has been done which gives most optimized results [2]. A research of standalone hybrid renewable system is conducted for Nooriabad an area of Thatta district of Pakistan. In this research two most optimized systems are proposed for electrification of the area, one consist of Solar PV (Photovoltaic)-Wind-Diesel-Battery hybrid system and the other consist of Solar PV-Wind-Battery system. The feasibility report shows that COE and NPC are optimized, which are 0.450 (US\$/kWh) and US\$ 359,465 respectively provided by the PV-Wind-Diesel-Battery hybrid system [3].

Another, economical research has been done by using HOMER for a village Malo Bheel Tharparkar, Sindh, Pakistan. This village consist of 57 houses with average load of $110(\mathrm{kWh} / \mathrm{d})$ with peak of $11 \mathrm{~kW}$. The proposed research consists of Solar-Wind-Battery hybrid power system which gives COE 0.13 (US\$/kWh) and NPC is US\$ 66,445 [4]. Likewise, another research of PV-wind hybrid system is proposed for Resham-Jo-Tar, Sindh, Pakistan. The electrical load of the area is $149(\mathrm{kWh} / \mathrm{d})$ with $19 \mathrm{~kW}$ peak. The feasibility research report shows optimized COE is 0.094 (US\$ $/ \mathrm{kWh}$ ) with share of $74 \%$ solar and $26 \%$ of wind resources [5].

A research for Pune in India has been proposed, in which the solar and wind resources are used through HOMER for providing uninterruptable and optimized electricity to cellular mobile base stations [6]. Similarly, another optimal system for BTS (Base Transceivers Station) for Oromia, Ethopia was proposed which consist of wind, PV and battery. This optimized system gives low cost of energy as compared to current diesel operated station and drastically reduces the emissions [7].

An off-grid micro gird has been proposed for Local Municipality, Eastern Cape, South Africa, the system consists of Wind-Diesel generator micro gird which offers COE of US\$ 0.320/kWh [8]. Another research has been done for Ramgarh village, Haryana State, in India. This standalone system consists of PV-Wind-Biogas resources, there are two feasible proposed schemes are planned, scheme-1 gives the least environmental emissions and scheme 2 gives the least levelized COE and NPC [9].

An economic study of hybrid renewable system was proposed by using HOMER for a community of Tor Sinai city of Egypt. This research has proposed PV-WindBattery system with a backup Diesel generator gives the optimized results contain COE US\$ 0.179/kWh [10]. Moreover, another system is proposed for the tourist sectors in South China Sea, Malaysia which totally depend on diesel generator electricity. The proposed research comprises of $\mathrm{PV}$-wind-diesel generator-battery-converter which provides optimized COE and significantly reduces the emissions [11].

In this paper, a research methodology of pursuing the non-renewable hybrid sources has elaborated and implemented. Due to blessing of having all the seasons and all varieties of nature, Pakistan has always been bestowed. The two main (non-hydro) renewable sources solar, and biomass has been stated which is implemented through different schemes of hybridization for the specific village of Pakistan.

The data has been collected by counting and estimating the number of loads per house, present in that area. Moreover, animal (Cow) dung is used for the production of anaerobic biogas energy is calculated through present statistics of cattle in given area. For solar PV source solar irradiance is calculated by giving exact coordinates in HOMER input data.

The COE and NPC has been optimized and briefly discussed for the selected village. From the simulation results of two most optimized cases has been taken which would be feasible for implementation and their comparison is done with the COE of diesel generator. 
These types of researches of standalone hybrid renewable system can be executed by implementing self-sustained systems under the current power sectors of the countries around the world. A small sized staff could be hired from these remote areas, after technical training they can be employed for operation and management of these systems. Same like in Pakistan, the implementation of this research for rural areas would not only be economical but also be beneficial as clean and safe energy for the residents. The AEDB (Alternative Energy Development Board) of Pakistan which is working under Ministry of Energy Division, can come forward for implementation, facilitation, and promotion of standalone hybrid renewable systems for rural development.

\section{METHODOLOGY}

This paper primarily focuses on optimization of hybrid system containing Solar and biogas energy for the proposed village. This research is simulated on HOMER Legacy v2.68 beta software for optimization of the system.

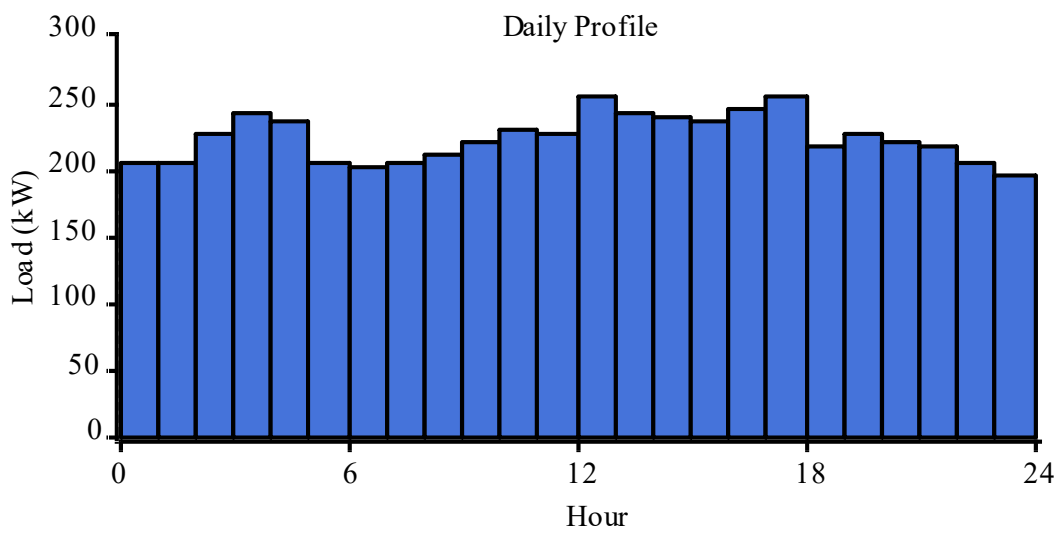

FIG. 1. LOAD PROFILE OF THE COMMUNITY

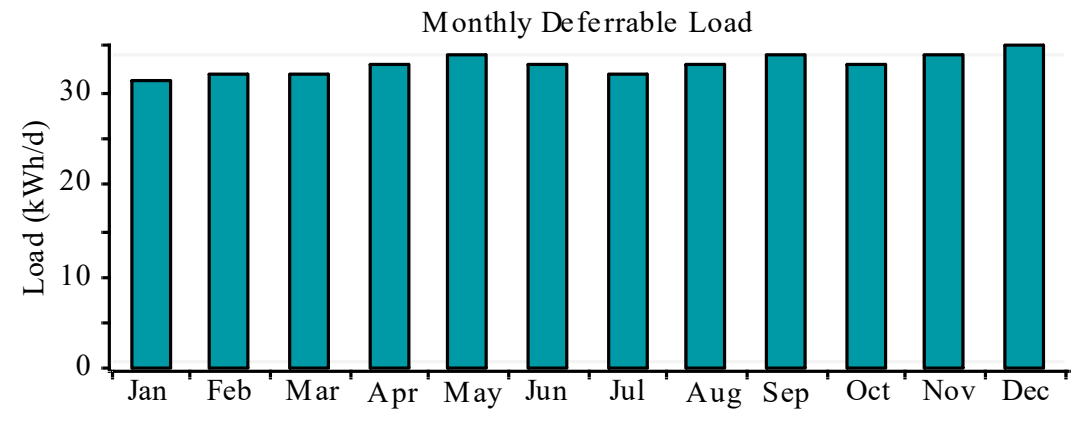

FIG. 2. DEFERRABLE LOAD PROFILE

\subsection{Load Profile Assessment of the Village}

The village comprises more than of 80 houses with some shops and one school, each house consists of 5-7 members. The electric load survey was conducted by visiting the area and collecting the data from various types of consumers. Unlike urban areas, the houses are distant from one another and inhabitants of the area uses diesel generators for household loads and operation of tubewells for agriculture purposes. The primary household load is included with light bulbs, fans and other household appliances. While the deferrable load is included with timely requirement of the load like water pumps and small sized motor appliances etc. The average primary load of each house is considered $2.5(\mathrm{kWh} / \mathrm{d})$ including their domestic (fans, bulbs, and various household appliances) and agriculture (tube-well pumps) utilization. The primary load demand of the village is 240 $\mathrm{kWh} / \mathrm{d}$ with peak of $20 \mathrm{~kW}$ and the deferrable load is 34 $\mathrm{kWh} / \mathrm{d}$ with peak of $3.5 \mathrm{~kW}$. The primary and deferrable load profile of the village is given in Figs. 1-2 respectively. 


\section{$2.2 \quad$ Solar Energy Sources}

The global horizontal irradiance has been calculated by HOMER through coordinates. The coordinates for installation of solar PVs of this village are about latitude 28.98 and longitude 71.57. HOMER calculates the scaled monthly annual average and clearance index. The scaled annual average is $5.7 \mathrm{kWh} / \mathrm{m}^{2}$ per day and average clearance index is 0.641 . Thus, Fig. 3 demonstrates solar irradiance of the site taken from HOMER.

\subsection{Biomass Sources}

The cow manure is widely available in this village of Cholistan and has abundant supply to meet the major portion of energy requirements. At least each house has
1-2 cattle (Cow) for their dairy purposes. The average dung from a cow is $20 \mathrm{~kg}$ /day which produces one cubic meter of biogas that yields of $2 \mathrm{~kW}$ electricity per day [12]. Thus if we take at least 80 cow's manure, then yields 80 cubic meter of biogas it will be able to produce almost $160 \mathrm{~kW}$. So the availability of manure is little bit more than the manure required for biogas generation. Moreover, the available manure is ample and meets the requirements of biogas generation for both types of proposed optimized hybrid systems. The minimum biomass potential of this village is estimated as 1.1 tons/day and monthly biomass potential generated would approximately be 33 tons. The gasification ratio is taken as $0.7 \mathrm{~kg} / \mathrm{kg}$ and the Lower Heating value of biogas is $5.5 \mathrm{MJ} / \mathrm{kg}$. The monthly stock of biomass sources is shown in Fig. 4.

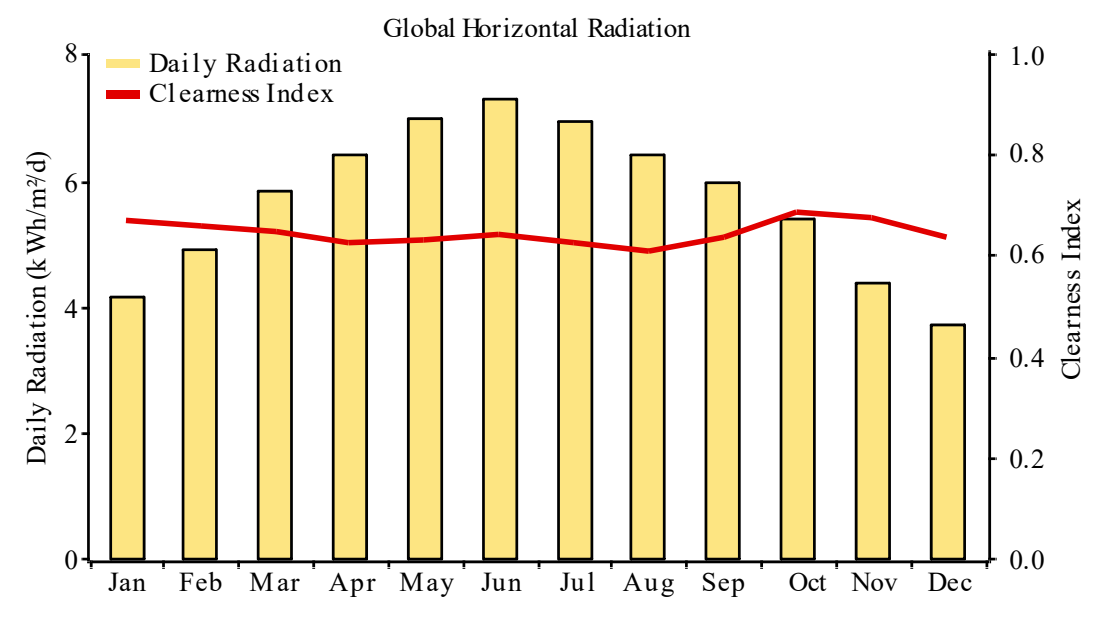

FIG. 3. SOLAR IRRADIANCE ON THE SITE OVER THE YEAR

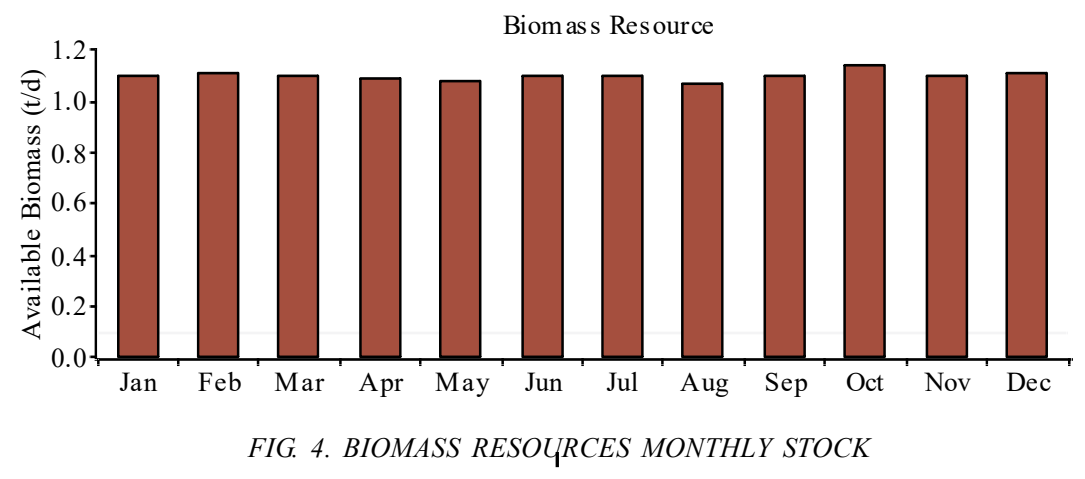

Mehran University Research Journal of Engineering \& Technology, Volume 38, No. 2, April, 2019 [p-ISSN: 0254-7821, e-ISSN: 2413-7219] 
The average regular collection of the biomass would remain more or less constant throughout the year. The efficiency of the biogas generator can be calculated by the formula which is fed to the dual fuel engine asin Equation (1) [13].

$\eta=\frac{\mathrm{kW}}{\mathrm{m} . \mathrm{H}}$

where $\mathrm{kW}$ is the rated output power of the generator,mis the biogas consumption rate, and $\mathrm{H}$ is the lower heating value of biogas.

Efficiency Curve: The efficicency of the biogas generator is presented in Fig. 5, which is taken from HOMER simulation, shows the direct relation between efficiency vs. output (\%).

\subsection{Battery}

The Surette 6CS25P battery has been selected from HOMER. The life time of these batteries is $9645 \mathrm{kWh}$ (6.94 $\mathrm{kWh}$ ), nominal capacity is $1150 \mathrm{Ah}$, and nominal voltage is $6 \mathrm{~V}$. The number of the batteries is selected according to desired amount energy which should be

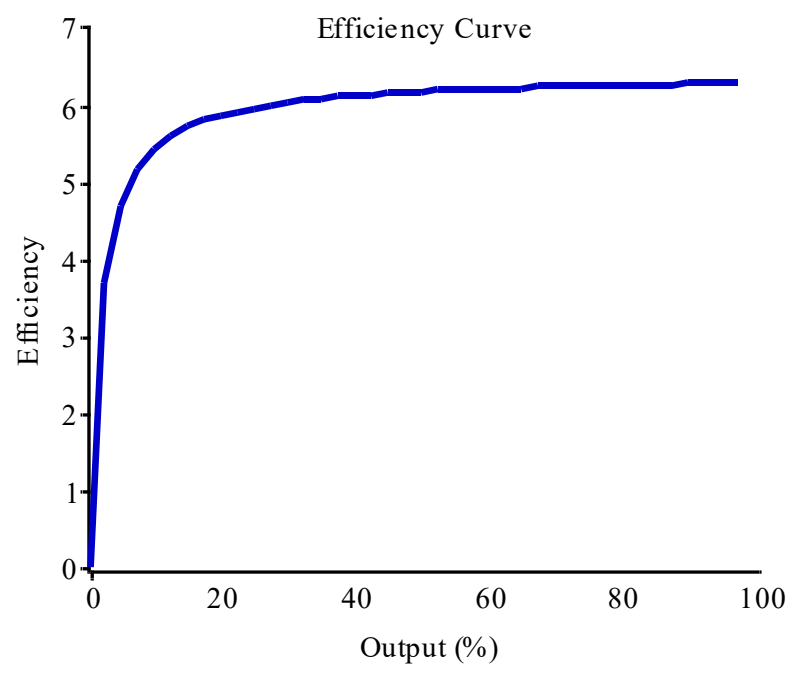

FIG. 5. EFFICIENCY CURVE OF BIOGAS GENERATOR stored at a time. The per unit battery price is US\$ 1179 [14]. In Fig. 6, the cost curve of the battery is clearly viewed.

\subsection{Converter}

Two inverters are selected according to the desired amount of which is to be converted. A $200 \mathrm{~kW}$ and a 150 $\mathrm{kW}$ converters are selected for inverting solar DC energy into $\mathrm{AC}$ energy. These two converters are proposed accroding to the ratings of Solar PV modules for the two most optimized systems. The HOMER software picks up the most suitable converter according to the desired values of Solar PV system which DC voltage output is to be converted for specific simulations. The technical specifications of converter are its input voltage of $380 \mathrm{~V}$ with variable output voltage of $0-380 / 480 \mathrm{~V}$. The operating frequency is $50 \mathrm{~Hz}$ and ouptut current is $380 \mathrm{~A}$. The price of the converter is taken US\$ 4320 [15].

\section{HYBRID SYSTEM MODELING}

The system is designed to meet energy requirements; the area has plenty of solar radiations and biomass resources

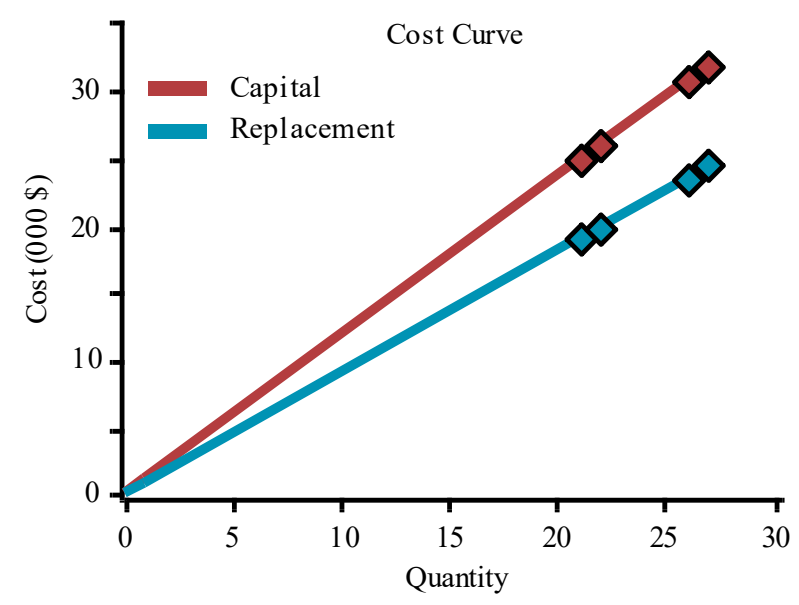

FIG. 6. COST CURVE OF THE BATTERY 6CS25P 
for production of electricity. The combination of Solar PV and Biogas sources would feasible for designing the standalone hybrid system for this community. A hybrid system containing Solar PV-Biogas-batteries-converter are used for making this optimized hybrid system. A diesel generator is used to compare the COE with this proposed off-grid hybrid system. Furthermore, PV capital multiplier is used to as sensitivity variable which defines, whether the price of PV panels may decrease then how much it will effect on the optimized cost of NPC and COE. The screenshot of Solar PV-Biogas hybrid system is shown in Fig. 7.

\section{HOMER INPUT SUMMARY}

The costs comprising capital costs, replacement costs, O\&M (Operation \& Maintainance) costs of each equipmemt, which are contributed in HOMER as inputs are shown in Table 1.

The cost of Solar PV panels are included with installation price and other equipments like cables, junction boxes and stands [16].

The price of biogas generator has been included with prices of digester, biogas balloons, and other auxiliaries [17].

\section{SIMULATION RESULTS AND DISCUSSION}

The two most optimized systems were taken from the feasible combinations of HOMER simulation. These systems are considered as most effective and optimized in terms of COE and NPC.

\subsection{Most Optimized Hybrid System}

The most optimized system is the one which gives maximum feasible COE and has been selected with following component's rating as stated in Table 2 .

The most optimized hybrid system provides COE 0.128 (US\$/kWh) with PV multipleir 1, 0.123 (US\$/kWh)with multiplier 0.9 and 0.117 (US\$/kWh) with multiplier 0.8 , that is specified in Table 3.

\subsection{Second Most Optimized Hybrid System}

The second most optimized system has been selected with following component's ratings as stated in Table 4.

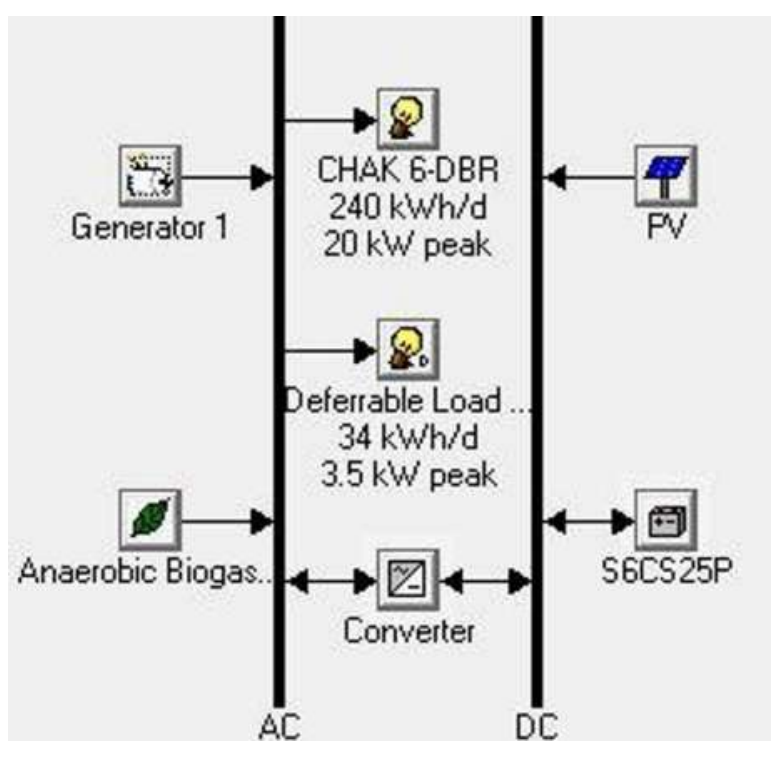

FIG. 7. SOLAR/BIOMASS HYBRID MODEL

TABLE 1. HOMER COMPONENTS INPUT SUMMARY

\begin{tabular}{|c|c|c|c|c|}
\hline HOMER Modules & $\mathrm{kW}$ & $\begin{array}{c}\text { Capital Cost } \\
\text { (US\$) }\end{array}$ & $\begin{array}{c}\text { Replacement Cost } \\
\text { (US\$) }\end{array}$ & $\begin{array}{c}\text { O\&M Cost } \\
\text { (US\$/Year) }\end{array}$ \\
\hline Solar PV & 180 & 72000 & 55000 & 0.00 \\
\hline Biogas & 100 & 30000 & 20000 & 0.30 \\
\hline Battery (Ah) & 1150 & 1179 & 900 & 5.00 \\
\hline Converter & 200 & 4320 & 4320 & 0.00 \\
\hline
\end{tabular}

Mehran University Research Journal of Engineering \& Technology, Volume 38, No. 2, April, 2019 [p-ISSN: 0254-7821, e-ISSN: 2413-7219] 
The second most optimized hybrid system provied COE 0.132 (US\$/kWh) with PV multipleir 1, 0.128 (US\$/kWh) with multiplier 0.9 and 0.123 (US\$/kWh) with multiplier 0.8 , that is specified in Table 5 .

The production from Solar PV is 263,734 kW/year, which is $65 \%$ of total load and biogas generator produces 140,400
$\mathrm{kW} /$ year which is $35 \%$ of total installed capacity of hybrid system as shown in Table 6.

The energy consumption of both primary and deferrable loads has been elaborated with their percentage share described in Table 7.

TABLE 2. COMPONENT SUMMARY OF THE MOST OPTIMIZED HYBRID SYSTEM

\begin{tabular}{|c|c|c|}
\hline No. & Components & Ratings \\
\hline 1. & Solar PV & $180(\mathrm{~kW})$ \\
\hline 2. & Biogas Generator & $100(\mathrm{~kW})$ \\
\hline 3. & Battery & $26(\mathrm{Quantity})$ \\
\hline 4. & Converter & $200(\mathrm{~kW})$ \\
\hline
\end{tabular}

TABLE 3. RESULTS OF THE MOST OPTIMIZED HYBRID SYSTEM

\begin{tabular}{|c|c|c|}
\hline No. & Different Costs & Prices \\
\hline 1. & Capital Cost & 136,974 (US\$) \\
\hline 2. & Operating Cost & 125 (US $\$ /$ year) \\
\hline 3. & NPC & $0.128($ US $\$ / \mathrm{kWh})$ \\
\hline 4. & COE & $0.123(\mathrm{US} \$ / \mathrm{kWh})$ \\
\hline 5. & COE with PV Multiplier of 0.9 & 0.117 (US $\$ / \mathrm{kWh)}$ \\
\hline 6. & COE with PV Multiplier of 0.8 & \\
\hline
\end{tabular}

TABLE 4. COMPONENT SUMMARY OF THE SECOND MOST OPTIMIZED HYBRID SYSTEM

\begin{tabular}{|c|c|c|}
\hline No. & Components & Ratings \\
\hline 1. & Solar PV & $140(\mathrm{~kW})$ \\
\hline 2. & Biogas Generator & $150(\mathrm{~kW})$ \\
\hline 3. & Battery & $21($ Quantity) \\
\hline 4. & Converter & $150(\mathrm{~kW})$ \\
\hline
\end{tabular}

TABLE 5. RESULTS OF THE SECOND MOST OPTIMIZED HYBRID SYSTEM

\begin{tabular}{|c|c|c|}
\hline No. & Different Costs & Prices \\
\hline 1. & Capital Cost & 138,999 (US\$) \\
\hline 2. & Operating Cost & 168,510 (US\$) \\
\hline 3. & NPC & 0.132 (US $\$ / \mathrm{kWh})$ \\
\hline 4. & COE & $0.128(\mathrm{US} \$ / \mathrm{kWh})$ \\
\hline 5. & COE with PV Multiplier of 0.9 & $0.123(\mathrm{US} \$ / \mathrm{kWh})$ \\
\hline 6. & COE with PV Multiplier of 0.8 & \\
\hline
\end{tabular}

Mehran University Research Journal of Engineering \& Technology, Volume 38, No. 2, April, 2019 [p-ISSN: 0254-7821, e-ISSN: 2413-7219] 


\subsection{Comparison of Different COEs}

The comparison of three systems' COEs among most optimized, second most optimized and fixed generation cost diesel generator has been specified in Table 8 .

It can be seen that COEs of the most and second most optimized system are much less than that of fixed generation cost of diesel generator taken from HOMER. Conclusively, it can be said that both optimized hybrid systems are utmost feasible for the proposed remote area as compared to electricity generated from fossil fuels.

\section{RESULTS AND DISCUSSION}

The current overall energy tariff of Pakistan varies between 0.14 and $0.19 \mathrm{US} \$ / \mathrm{kWh}$. The energy generated from the most optimized hybrid system has COE of $0.128(\mathrm{US} \$ \mathrm{kWh}$ ) which is less than current energy tariff of the country. Moreover, the sensitivity parameter of Solar PV cost multiplier has also taken into consideration with multiplier of $1,0.9$, and 0.8 . This standalone proposed hybrid system has many advantages for the village. Some of the main advantages of standalone hybrid renewable systems is that is ineffective by the problems, like variations in diesel prices, line losses and load shedding. This proposed optimized hybrid system has excess electricity which can be used to meet aggravating future energy demands of the community. HRDP system can be more effective and inexpensive as compared to the thermal (Furnace Oil) electricity. HRDP has one major advantage over all other supplies of electricity that it can be installed at any distant place where the grid electricity is out of reach from any specific community.

TABLE 6. PRODUCTIONS FROM DIFFERENT RENEWABLE SOURCES

\begin{tabular}{|c|c|c|}
\hline Production & kWh/Year & $\%$ \\
\hline Solar PV & 263,734 & 65 \\
\hline Biomass & 140,400 & 35 \\
\hline Total & 404,143 & 100 \\
\hline
\end{tabular}

TABLE 7. ENERGY CONSUMPTION

\begin{tabular}{|c|c|c|}
\hline Consumption & KWh/Year & $\%$ \\
\hline Primary load & 87,600 & 88 \\
\hline Deferrable load & 12,412 & 12 \\
\hline Total & 100,012 & 100 \\
\hline
\end{tabular}

TABLE 8. COMPARISON OF COE OF MOST OPTIMIZED SYSTEM WITH DIESEL ENGINE

\begin{tabular}{|c|c|}
\hline System Type & COE (US\$/kWh) \\
\hline Most Optimized PV/Biogas Hybrid & 0.128 \\
\hline 2nd Most Optimized PV/Biogas Hybrid & 0.132 \\
\hline Diesel Generator & 0.175 \\
\hline
\end{tabular}




\section{CONCLUSION}

In this paper, the optimization results of hybrid PV/Biogas system is briefly elaborated by using HOMER simulation. In remote areas, where the electricity is out of reach, a standalone hybrid renewable system can be installed. The COE and NPC of optimized hybrid system is compared with grid electricity which is very economical and environment friendly for rural areas. Two most optimized systems are considered best for the selected community which can be installed. The proposed optimized hybrid system offers COE US\$ 0.128/ kWh and NPC US\$ 164,134. The optimized COE is $30 \%$ less than that of energy produced from fixed generation cost of diesel generator. Although the optimal conditions simulated by software sometimes cannot fulfill the entire requirements, so the second most optimized case can be considered as the best. This type of proposed standalone hybrid system can be a role model for other remote areas of Pakistan where the grid electricity is difficult to extend and it may also be implemented at large level to serve the huge demand of electricity for massive communities.

\section{ACKNOWLEGDEMENT}

Authors are thankful to the Department of Electrical Engineering, The Islamia University of Bahawalpur, Bahwalpur, Department of Electrical Engineering, University of Engineering \& Technology, Pakistan, and residents of the village for their valuable support and cooperation.

\section{REFERENCES}

[1] Vincietal, S., "Energy Access Outlook 2017: From Poverty to Prosperity," International Energy Agency, Volume 94, No. 3, pp. 116, 2017.

[2] Sharma, N.K., and Mishra, R., "Optimal Design of Hybrid Renewable Energy System for a Sustainable Energy Development of a Village in Rajasthan", International Journal of Science and Research, Volume 5, No. 4, pp. 952-954, 2016.
[3] Rehman, S., Shoaib, M., and Lashin, A., "Feasibility Study of Hybrid Energy System for Off-Grid Rural Electrification in Southern Pakistan", Energy Exploration and Exploitation, Volume 34, No. 3, pp. 468-482, 2016.

[4] Meghwar, A., Haq, L., and Irshad, N., "Techno Economic Evaluation of Off-Grid Hybrid Solar-Wind Power System for Village MaloBheel, Tharparkar Sindh Pakistan", American Journal of Energy and Research, Volume 5, No. 2, pp. 28-34, 2017.

[5] Tunio, N.A., Mangrio, Z.A., Hajano, M.A., Soomro, A., and Jumani, T.A., "Economic and Technical Study of Hybrid System (Wind-Photovoltaic) Electrification for Rural area of Tharparkar District, Sindh Using HOMER Software", International Conference on Energy, Environment and Sustainable Development, Volume 4, 2016.

[6] Sawant, B., "HOMER Optimization Based Solar", International Journal for Research in Engineering Application \& Management, Volume 4, No. 1, pp. 1-5, 2016.

[7] Yeshalem, M.T., and Khan, B., "Design of an Off-Grid Hybrid PV/Wind Power System for Remote Mobile Base Station: A Case Study", AIMS Energy, Volume 5, No. 1, pp. 96-112, 2017.

[8] Longe, O.M., Rao, N.D., Omowole, F., Oluwalami, A.S., and Oni, O.T., "A Case Study on Off-Grid Microgrid for Universal Electricity Access in the Eastern Cape of South Africa", International Journal of Energy Engineering, Volume 7, No. 2, pp. 55-63, 2017.

[9] Saraswat, R., and Sathans S., "Optimum Scheduling of Isolated Hybrid Renewable Energy System - A Case Study Using HOMER", Journal of Environmental and Analytical Toxicology, Volume 7, No. 6, pp. 1-10, 2017

[10] Abed, K.A., Moawad, M., and Refaey, H.A., "TechnoEconomic Study of Hybrid Renewable Energy System for Remote Area in Sinai”, Journal of Scientific and Engineering Research, Volume 4, No. 7, pp. 366-376, 2017.

[11] Hossain, M., Mekhilef, S., and Olatomiwa, L., "Performance Evaluation of a Stand-Alone PV-WindDiesel-Battery Hybrid System Feasible for a Large Resort Center in South China Sea, Malaysia", Sustainable Cities and Society, Volume 28, pp. 358-366, 2017. 
[12] Perfect Biogas Generators, "Electricity from Cow Dung”,[Online]. Available:http://www.perfectbiowaste power.in/electricty-from-cow-dung.htm (Last Visited: $24^{\text {th }}$ February, 2018).

[13] Raheem, A., Hassan, M.Y., and Shakoor, R., "Economic Feasibility of Stand-Alone Wind Energy Hybrid with Bioenergy from Anaerobic Digestion for Electrification of Remote Area of Pakistan", International Journal of Integrated Engineering, Volume 6, No. 3, pp. 1-8, 2014.

[14] Webosolar, "Surrette 6-CS-25-PS", [Online]. Available:https://www.webosolar.com/store/en/deepcycle-batteries/993-surrette-rolls-6-cs-25ps-1150-ah-6volt-deep-cycle-battery.html(Last Visited: $25^{\text {th }}$ February, 2018).
[15] Shenzhen, "3-Phase Solar Power 200kW”, [Online]. Available:https://www.alibaba.com/product-detail/3Phase-Solar-Power-200KW-solar_60651426042.html? $\mathrm{spm}=\mathrm{a} 2700.7724857$. main07.58.758a74a6L2Byearm.html (Last Visited: 26 $6^{\text {th }}$ February, 2018).

[16] Huaian, "Solar Panel System", [Online]. Available:https:/ /www.alibaba.com/product-detail/YuanChan-Top-One315 W-Solar-Panel_60386789350.html?spm=a 2700.details.maylikever.11.4f9999caQKt8yw.html(Last Visited: $26^{\text {th }}$ February, 2018).

[17] Camda, "Biogas Cogeneration Plant", [Online]. Available:https://www.alibaba.com/product-detail/100200kW-Biogas-cogeneration-unit-Biogas_1648716349. html(Last Visited: 26 $6^{\text {th }}$ February, 2018). 